\title{
Large eddy simulation of impinging flames: Unsteady ignition and flame propagation
}

\author{
Yiran Chen ${ }^{\mathrm{a}}$, Tong $\mathrm{Yao}^{\mathrm{a}}$, Qian Wang ${ }^{\mathrm{b}, *}$, Kai Hong Luo ${ }^{\mathrm{a}, \mathrm{c}, *}$ \\ ${ }^{a}$ Center for Combustion Energy, Key Laboratory for Thermal Science and Power \\ Engineering of Ministry of Education, Department of Thermal Engineering, Tsinghua \\ University, Beijing 100084, China \\ ${ }^{b}$ School of Mechanical Engineering, Shanghai Jiao Tong University, Shanghai 200240, \\ China \\ ${ }^{c}$ Department of Mechanical Engineering, University College London, Torrington Place, \\ London WC1E 7JE, UK
}

\begin{abstract}
The dynamic processes of ignition and turbulent flame development in a turbulent impinging flame are studied using large eddy simulation (LES). The Dynamic Thickened Flame (DTF) model is extended to incorporate realistic chemical mechanisms to simulate the partially premixed flames due to flame impingement on a solid wall. A new chemical mechanism with 22 species 66 steps is developed for propane. This LES formulation correctly reproduces the different ignition and turbulent flame dynamics under three differnt ignition conditions corresponding to experiments. Combustion modes formed by the impinging propane flame are investigated using flame indicator and chemical explosive modes analysis, which reveals the existence of both turbulent premixed and diffusion flames. The extent and strength of premixed and diffusion flame modes, respectively, are strongly influenced by the ignition location relative to the wall. The corresponding thermal expansion leads to different flow and mixing processes, which in turn affects the subsequent flame development. The variation of the overall heat release with time is different for the three ignition locations, reflecting different contributions from the premixed and diffusion
\end{abstract}

\footnotetext{
${ }^{*}$ Corresponding authors

Email addresses: qianwang@sjtu.edu.cn (Qian Wang), k.luo@ucl.ac.uk (Kai Hong Luo)
}

Preprint submitted to Fuel

April 24, 2019 
flames, respectively.

Keywords: impinging flame, large eddy simulation, ignition and

propagation, chemical explosive mode analysis (CEMA)

2010 MSC: 00-01, 99-00

\section{Introduction}

Impinging flames typically consist of a jet flame region, a stagnation region and a wall-flame region, which are of significant practical and theoretical importance. In industry, impinging flames are used in metal processing, glass making,

5 soldering, welding, and so on. Impinging flames are also found in combustion engines, by design and/or by accident, which have a major effect on combustion characteristics, heat transfer and emissions. As impinging flames have very different characteristics from those of the widely investigated free jet flames, the study of impinging flames is of fundamental interest to the research communities on heat transfer 1, 2, fluid mechanics and combustion 3, 4, 5, 6. A large number of parameters are involved in impinging flames, which adds to the complexity of the problem. These include the jet-to-wall distance, jet inclination relative to the impingement plate, Reynolds number and Mach number as well as the numerous parameters for fuels and combustion. In most applications, the 15 Reynolds number is high enough for impinging flames to become turbulent.

Impinging flames have been extensively studied theoretically, experimentally and numerically. Hou et al. 7] showed that the flame shape and temperature distribution varied with different jet-to-wall distances in a methane/air premixed flame $(\mathrm{Re}=365)$. $\mathrm{CO}$ emissions of both non-premixed and premixed impinging flames were studied experimentally/numerically in [8, 9]. Turbulent impinging inverse diffusion flames [10, 11, 12] and turbulent partially premxied impinging flames [13, 14] were investigated where results for different wall-nozzle distances and equivalence ratios were compared. When analyzing impinging flames, it is of great value to measure the flame temperature and flow quantities near the stagnation point. However, measuring these quantities in the near-wall region 
are challenging and few results have been reported. A PIV system was used to measure the velocity field in an impinging annular jet [15], and the results showed that the velocity field near the impinging surface was sensitive to jet settings. The temperature field was measured by the Mach-Zehnder interferometer 30 in 16$]$.

Direct numerical simulation (DNS) has been carried out for flame-wall interactions. Turbulent impinging flames $(\mathrm{Re}=2000)$ of $\mathrm{H}_{2} / \mathrm{CO}$ were simulated, with the Flamelet Generated Manifold (FGM) for chemical reactions by Dinesh et al [17], indicating that high $\mathrm{H}_{2} / \mathrm{CO}$ ratio would induce local extinction in jet region and thus resulting in a different flame structure compared with low $\mathrm{H}_{2} / \mathrm{CO}$ ratio flames. Effects of different levels of inlet perturbations were simulated in [6] and the results showed that external perturbations would not significantly change the near wall combustion behaviour due to relaminarization. Buoyancy effects on the impinging flame structure were discussed in [4, 5], demonstrating

40 that buoyancy functions as an oscillator and the vortical structures would be affected.

Besides DNS investigations, large eddy simulation (LES) has also been used to study impinging flames. Martinez et al. [18] used a reduced mechanism to investigate the fuel variability on impinging flame dynamics and made similar 45 conclusions as in [17. FGM with an artificially thickened flame (ATF) model was used for premixed impinging flames [19]; and good agreement was achieved between LES results and experiments by applying a non-adiabatic FGM table. ATF with directly solved one-step chemistry was also implemented in LES [20] to evaluate the effects that different heat boundary conditions have on impinging flames. LES with detailed chemistry was carried out [21] and the result showed that significant difference occured in the deflection zone near the stagnation region.

For both DNS and LES studies, detailed chemical kinetic mechanisms in turbulent combustion processes have attracted notable attentions in recent years.

${ }_{55}$ More general mechanisms considering different species, temperature, pressure and fuel/air ratio have been developed. Qin et al. 22, have developed a de- 
tailed mechanism consisting of 70 species and 463 reactions for propane oxidation. This mechanism was optimized later and incorporated into the systematic mechanism USC MECH II for C0-C4 oxidation. Detailed mechanisms for propane can consist of hundreds of species and reactions when low temperature chemistry is involved [23, 24, 25]. For instance, the detailed mechanism developed by Gallagher et al. [23] consists of 118 species and 663 reactions. Such large mechanisms need to be reduced for computationally tractable threedimensional (3-D) simulations. Reduced mechanisms for propane have been developed from detailed chemistry [26, 27, 28, 29], and employed successfully for Reynold-Averaged CFD simulations [28, 29]. For example, Jithin et al. [29] have performed a three-dimensional simulation to investigate steady laminar premixed propane-air flames using a reduced mechanism with 30 species and 192 reactions. However, these reduced mechanisms are still unaffordable 70 for advanced numerical techniques like 3-D LES. Currently, most LES studies [30, 31, 32 are using either a global scheme or reduced mechanisms with only a few steps, which are incapable of accurately predicting flame behaviors e.g. flame speed and flame structures. In the present work, we develop a reduced mechanism of propane consisting of 22 species and 66 reactions, which is not only sufficiently accurate for predicting turbulent combustion characteristics but also more suitable and economic than the existing detailed mechanisms for implementation in LES.

With most studies focused on steady-state impinging flame properties, the behaviours of unsteady-state impinging flame are of particular interest. For premixed impinging flames, different flame structures were observed for different ignition locations with the same pre-ignition flow conditions [33, 34. Moreover, flame structures in non-premixed impinging flames were also sensitive to initial ignition conditions [35]. These studies demonstrated that different combustion modes could result from the same pre-ignition condition with different ignition settings. Experimental techniques including PIV, Mach-Zehnder interferometer and Digital Flame Color Discrimination can be used to measure velocity, temperature and species concentration fields. However, it is still difficult to obtain 
time- and space-resolved experimental data to distinguish local premixed and diffusion flame modes in the near-wall regions. Therefore, numerical simulations are are needed to provide full-field information over time in order to identify local flame structures and to reveal the underlying mechanisms for unsteady behaviours in turbulent impinging flames.

This paper extends previous studies on ignition to include the effects of ignition locations where local fuel/air mixing conditions differ in an impinging flame configuration. In particular, an improved LES model is developed to simulate turbulent partially premixed flames including both premixed and diffusion flames simultaneously. An accurate 22 species 66 steps propane mechanism is developed to improve the chemical description of ignition and flame development. A non-premixed propane impinging flame with $\mathrm{Re}=4280$ and large ratio $\mathrm{H} / \mathrm{d}=32.823$ is simulated, where $\mathrm{H}$ and $\mathrm{d}$ represents the wall-nozzle distance and nozzle diameter, respectively. The ratio 32.823 is larger than that in most previous experiments, and the Reynolds number 4280 ensures fully turbulent conditions. The Dynamic Thickened Flame (DTF) model coupled with the realistic mechanism is implemented in a LES framework. The dynamic process of impinging flames after ignition and the effects of initial ignition locations are simulated by the LES-DTF solver, in combination with experimental studies [36].

\section{Methodology}

\subsection{LES with Dynamic Thickened Flame (DTF) Model}

The dynamic version of the Artificially Thickened Flame (ATF) model is implemented in the simulation to represent turbulence-flame interactions. The ATF was initially applied to laminar flames [37, 38. Angelberger et al. 39] and Colin et al. [40] extended it and developed an ATF model for LES of turbulent premixed flames. Since then, the ATF model and its derivatives have been widely used in LES of turbulent premixed flames [41, 42, 43, 44]. The basic idea of the ATF model is to broaden the flame thickness by a factor of $F$ 
$(F>1)$ so that the flame structure can be resolved on an LES grid. In order for the thickened flame to have the same laminar flame speed as the original one, diffusion coefficients (for heat and species transport) and chemical reaction rates have to be modified by a factor of $F$ and $1 / F$, respectively. The ATF model, however, modifies flame-turbulence interactions, as the flame thickening decreases the Damköhler number by a factor of $\mathrm{F}$ and makes the turbulent eddies less efficient in wrinkling the flame surfaces. An efficiency function $E(E>1)$ is introduced by Colin et al. [40] to account for the decreased flame surface wrinkling (and consequently reduced reaction rate). As shown in (Eq. 1 12 , diffusion coefficients $D_{i}$ are replaced by $D_{i} E F$ and the chemical source terms $\widetilde{\omega}_{i}$ are replaced by $E \widetilde{\omega_{i}} / F$ where $\mathrm{E}$ and $\mathrm{F}$ refers to the turbulent wrinkling efficiency function and the thickening factor, respectively.In this simulation, Lewis number is assumed to be 1 . There are different expressions for the efficiency function 40, 45, 46. In this paper, the expression by Colin et al. [40] is chosen (Eq. 3).

$$
\begin{gathered}
\frac{\partial \bar{\rho} \widetilde{Y_{i}}}{\partial t}+\nabla \cdot\left(\bar{\rho} \widetilde{\boldsymbol{U}} \widetilde{Y}_{i}\right)=\nabla^{2}\left(D_{i} E F \widetilde{Y}_{i}\right)+\frac{E \widetilde{\omega_{i}}}{F} \\
\frac{\partial \bar{\rho} \widetilde{h_{s}}}{\partial t}+\nabla \cdot\left(\bar{\rho} \widetilde{\boldsymbol{U}} \widetilde{h_{s}}\right)=\frac{d p}{d t}+\nabla^{2}\left(\alpha E F \widetilde{h_{s}}\right)+\frac{E \widetilde{\omega_{h}}}{F} \\
E=\frac{1+\alpha \Gamma\left(\frac{\Delta_{e}}{\delta_{l}}, \frac{u_{\Delta_{e}}^{\prime}}{s_{l}^{0}}\right) \frac{u_{\Delta_{e}}^{\prime}}{s_{l}^{O}}}{1+\alpha \Gamma\left(\frac{\Delta_{e}}{F \delta_{l}}, \frac{u_{\Delta_{e}}^{\prime}}{s_{l}^{0}}\right) \frac{u_{\Delta_{e}}^{\prime}}{s_{l}^{o}}} \\
\Omega=Y_{F}^{\nu_{F}} Y_{O}^{\nu_{O}} \exp \left(\Gamma \frac{-T_{a}}{T}\right)
\end{gathered}
$$

In the initial ATF formulation, $\mathrm{F}$ is taken as a constant, which means that the thickening is applied in the whole flow field, even where there is no reaction. This would affect the accuracy of simulating mixing and diffusion away from the flame zones. To overcome this shortcoming, Legier et al.47] introduced a flame sensor $\Omega$ in (Eq. 4 . $\Gamma(<1)$ is a constant. $\Omega$ varies with location and time, and detects the flame zone. $F$ is a function of $\Omega$ as in (Eq. 5). As a consequence, $\mathrm{F}$ attains the maximum value at the most active reaction zone but decreases 
with the reaction rate, reaching a value of about 1 in non-reacting regions (no thickening). The resulting model is called the dynamic thickened flame (DTF) model.

$$
F=1+\left(F_{\max }-1\right) \tanh \left(\beta \frac{\Omega}{\Omega_{\max }}\right)
$$

For one-step global reaction, the progress variable, temperature or reaction rate can be used to determine $\Omega$. For tabulated chemistry, $\Omega$ is commonly chosen as a function of a progress variable like $\Omega=16[c(1-c)]^{2}$ [20, 48]. For multisteps reduced mechanisms, a progress variable could still be defined and used, although an artificial one-step reaction rate can also be used to determine $\Omega$ [49], sometimes in combination with other quantities such as gradients of products [50. When implementing the DTF model with detailed chemistry, there is no established method for specifying $\Omega$. In the present study, we use the expression following the form of Eq. 4 and give the parameter values as in Eq. 6. Note that for propane/air combustion, a high $\nu_{F}$ value will result in overestimation of the reaction rate in fuel rich side, while low or negative $\nu_{F}$ value will cause numerical stiffness. Therefore $\nu_{F}=0.1$ and $\nu_{O}=1.6$ are chosen which should serve the purpose of providing an approximate flame sensor to determine the thickening factor $\mathrm{F}$.

$$
\Omega=Y_{C_{3} H_{8}}^{0.1} Y_{O_{2}}^{1.6} \exp \left(\frac{-3600}{T}\right)
$$

\subsection{Propane Mechanisms}

Two mechanisms for propane combustion are developed including a 26-step mechanism with 13 species (s13r26) and a 66-step mechanism containing 22 species (s22r66). The 66-step mechanism is derived in the present work, based on the detailed USC MECH II [51, which originally contains 111 species and 784 reactions. The USC MECH II has been validated thoroughly and could accurately predict propane combustion under a wide range of conditions. In the present work, mechanism reduction is conducted based on a decoupling strategy [52, 53, 54. A reduced sub-model for $\mathrm{C}_{3}$ decomposition is firstly developed and combined with semi-detailed $\mathrm{C}_{1}-\mathrm{C}_{2}$ sub-model and detailed $\mathrm{CO} / \mathrm{H}_{2}$ sub-modesl. 
According to the Reaction Flow Analysis (RFA) [55] of propane/air premixed combustion using the detailed USC MECH II, conversion of propane is dominated by $\mathrm{H}$-abstraction with the attack of radicals (e.g. $\mathrm{H}, \mathrm{O}, \mathrm{OH}, \mathrm{O}_{2}, \mathrm{HO}_{2}$ ) to produce propyl radicals $(\mathrm{R} 1-\mathrm{R} 5)$

$$
\mathrm{C}_{3} \mathrm{H}_{8}+\mathrm{R}=\mathrm{C}_{3} \mathrm{H}_{7}+\mathrm{RH}
$$

where $\mathrm{R}$ represents five radicals including $\mathrm{H}, \mathrm{O}, \mathrm{OH}, \mathrm{O}_{2}, \mathrm{HO}_{2}$. Then the propyl radicals decompose to $\mathrm{C}_{2} \mathrm{H}_{4}$ and $\mathrm{CH}_{3}$ through $\beta$-scission (R6)

$$
\mathrm{C}_{3} \mathrm{H}_{7}=\mathrm{C}_{2} \mathrm{H}_{4}+\mathrm{CH}_{3}
$$

The above 6 reaction steps along with 2 species (i.e. $\mathrm{C}_{3} \mathrm{H}_{8}, \mathrm{C}_{3} \mathrm{H}_{7}$ ) constitute the $\mathrm{C}_{3}$ decomposition sub-model. As a bridge between $\mathrm{C}_{3}$ sub-model and $\mathrm{CO} / \mathrm{H}_{2}$ sub-model, the $\mathrm{C}_{1}-\mathrm{C}_{2}$ sub-model mainly considers conversion of $\mathrm{C}_{2} \mathrm{H}_{4}$ to $\mathrm{CO}$. The reaction pathways for $\mathrm{C}_{2} \mathrm{H}_{4}$ consumption using the USC MECH II mechanism under various flame conditions were performed by Kumar et al. [56].

${ }_{125}$ The results are used as a reference here for reduction of the $\mathrm{C}_{1}-\mathrm{C}_{2}$ sub-model. Reaction pathways accumulatively contributing to, for example, $90 \%$ of the total consumption of the species upstream are retained, along with the relevant reactions. The semi-detailed $\mathrm{C}_{1}-\mathrm{C}_{2}$ sub-model obtained after reduction consists of 8 species and 35 reactions. Furthermore, a detailed $\mathrm{H}_{2} / \mathrm{CO}$ sub-model

${ }_{130}$ [57] consisting of 12 species and 25 reactions is added, resulting in a 66-steps mechanism with 22 species.

The mechanism s13r26 is developed by combining two sub-models, including a global sub-model for partial oxidation of $\mathrm{C}_{3} \mathrm{H}_{8}$ to $\mathrm{CO}$ and $\mathrm{H}_{2}$ and a detailed sub-model of $\mathrm{H}_{2} / \mathrm{CO}$ oxidation. The global sub-model for partial oxidation of $\mathrm{C}_{3} \mathrm{H}_{8}$ including the reaction of $\mathrm{C}_{3} \mathrm{H}_{8}+1.5 \mathrm{O}_{2} \rightarrow 3 \mathrm{CO}+4 \mathrm{H}_{2}$, which is taken from Westbrook and Dryer [58. The detailed $\mathrm{H} 2 / \mathrm{CO}$ oxidation sub-model is from [57.

Validations are performed for the newly developed propane mechanisms s22r66 and s13r26 in premixed flames under a wide range of equivalence ratios. Detailed simulations are conducted with the PREMIX program package 
[52]. A two-step global mechanism s6r2 from Jimenez et al. [59] is also used for comparison.

Results for laminar flame speeds under $p=1 \mathrm{~atm}$ are shown in Fig. 1 The s22r66 mechanism is able to match the laminar flame speed well with the detailed mechanism USC MECH II. The mechanisms s6r2 and s13r26 massively over-predict laminar flame speed on the fuel rich side, which will lead to large errors in the prediction of fuel-rich premixed combustion or any non-premixed combustion. Thus the equilibrium temperature and $\mathrm{CO}$ concentration for stoichiometric and fuel-rich cases are over-predicted. The flame structures under different equivalence ratios are shown in Fig. 2 (results of s13r26 are excluded as it provides no better prediction of laminar flame speed than s6r2). It is found that it is crucial to include reactions of intermediate species e.g. $\mathrm{C}_{2} \mathrm{H}_{4}$, $\mathrm{C}_{2} \mathrm{H}_{2}$ and $\mathrm{CH}_{4}$ in order to correctly reproduce combustion characteristics under rich mixture conditions. Mechanism s6r2 and s13r26, as well as other reduced mechanisms without these reactions, will inevitably lead to overprediction of the laminar flame speeds on the fuel-rich side. The s22r66 mechanism can be find in Appendix section and the relevant chemistry/thermo files are provided as supplementary materials.

\subsection{Impinging Flame Experiments and Computational Setup}

A series of turbulent impinging flames are studied experimentally using a configuration as illustrated in Fig. 33 35, 36]. The experimental system consists of a non-premixed jet burner with a central nozzle of $4.57 \mathrm{~mm}$ in diameter and a steel plate of $300 \mathrm{~mm}$ in diameter held by a steel frame. The impinging plate is $150 \mathrm{~mm}$ away from the nozzle exit. A high speed three-dimensional (3D) flame visualization and a high speed schlieren imaging system is utilized to record the dynamic processes of ignition and flame development under a variety of conditions. Advanced flame structure visualization and 3D digital reconstruction techniques have been developed to extract detailed flame structures for analysis.

The region within the dotted lines in Fig. $3 \mathrm{a}$ is chosen as the computational 


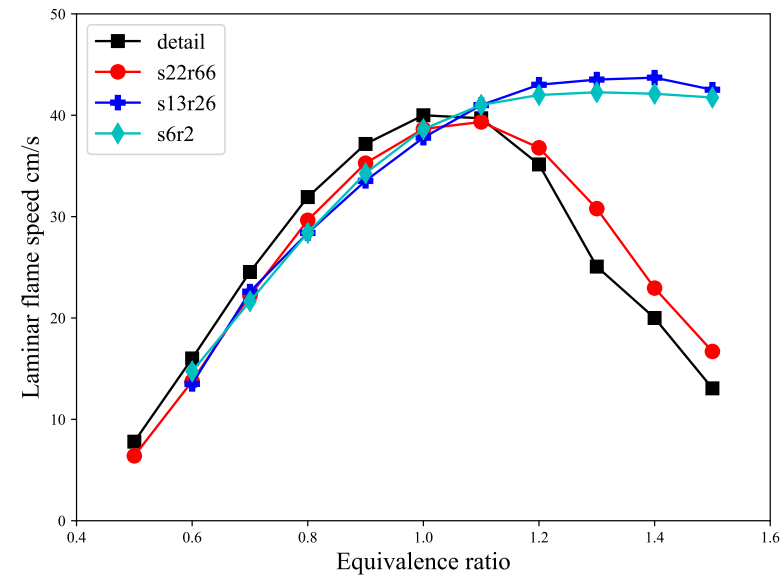

Figure 1: Laminar flame speeds for propane/air mixtures at $\mathrm{p}=1 \mathrm{~atm}$, initial temperature $\mathrm{T}_{0}=300 \mathrm{~K}$ and different equivalence ratios, calculated using mechanisms USC MECH II, s22r66, s13r26 and s6r2, respectively.

domain, which is of a cylindrical shape as shown in Fig. 3b. The upper and bottom walls are set to be non-slip walls. The side boundary is set to be pressure inlet and/or outlet. For outflow, zero gradient is applied while for inflow, pressure is used to calculate the inflow velocity at the boundary. At the jet inlet, the Random Spot method [60] is used to generate turbulence with eddies of different scales. The inlet velocity is $5 \mathrm{~m} / \mathrm{s}$ which is equivalent to a flow rate of $4.2 \mathrm{l} / \mathrm{min}$ of pure propane in the experiment. Inside the computational domain, there is pure air initially. The setup, in both the experiment and LES, is basically a turbulent non-premixed flame in the inlet region, although LES results in the later sections would confirm the existence of both premixed and non-premixed flames in this setup. The Wall-adapted Local Eddy-viscosity (WALE) model 61] is used in the LES for the flow field near the impinging surface.

The simulation grid is non-uniform. In the axial direction, the grid is fine 185 near the flow exit plane and impinging plate(around $0.2 \mathrm{~mm}$ ) and relatively coarse in the middle region (around $1 \mathrm{~mm}$ ). In radial direction, the grid is fine 


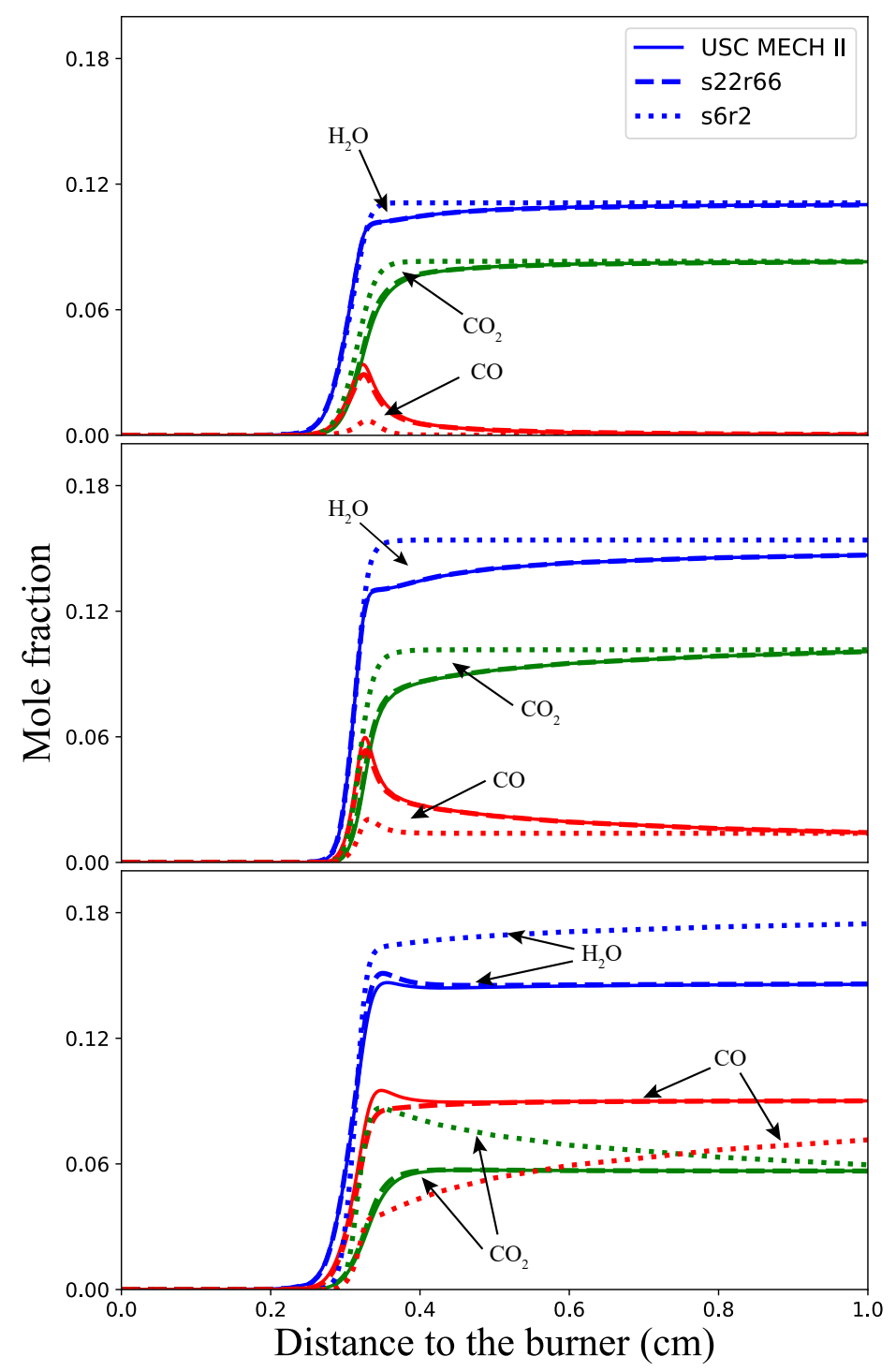

Figure 2: Laminar flame structures for propane/air mixtures at $\mathrm{p}=1$ atm and different equivalence ratios. left: $\phi=0.7$, middle: $\phi=1.0$, and right: $\phi=1.4$, calculated using the USC MECH II mechanism, reduced mechanisms s22r66 and s6r2, respectively. The s22r66 mechanism is able to match the flame structure with USC MECH II for both fuel-lean and fuel-rich conditions. 

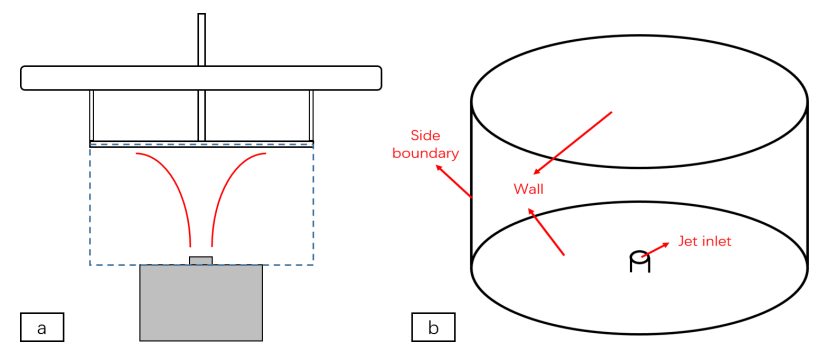

Figure 3: Diagrams for (a) the experimental setup and (b) the simulation domain

at $r=0 \mathrm{~mm}$ (around $0.3 \mathrm{~mm}$ ) and coarse at $r=150 \mathrm{~mm}$ (around $3 \mathrm{~mm}$ ). The DTF solver is developed based on OpenFOAM. Backward scheme is chosen as time scheme and central difference scheme is chosen as spatial scheme.

Before igniting the mixture, the cold flow is simulated for $1 \mathrm{~s}$. Three different ignition locations are chosen for the LES to match those in the experiment to study the influence of initial ignition conditions for the impinging flame. The three locations are chosen to be (1) near nozzle exit; (2) the middle point between the nozzle and the impinging surface; (3) near the impinging surface. The forced ignition by a spark is mimicked by a spherical heat source. The ignition heat source is temperature-dependent as expressed in (Eq. 7), where $\mathrm{T}_{\text {ignition }}$ is $1600 \mathrm{~K}$ and $\mathrm{Str}$ is a constant of 30000 . This source term could be regarded as a relaxation for temperature within a specific time period. The ignition source diameter is $3.5 \mathrm{~mm}$ and ignition duration is $4 \mathrm{~ms}$. This method could not reveal the real spark ignition process. However, as the same ignition source term is implemented for all the cases, the ignition method will not affect the comparison among the different cases, especially the subsequently flame propagation.

$$
S_{\text {ign }}=\operatorname{Str} \times\left(\frac{T_{\text {ignition }}-T}{T_{\text {ignition }}-T_{\text {unburnt }}}\right)^{0.8}
$$

\subsection{Construction of Numerical Schlieren Image}

To compare the simulation results with Schlieren images from experiments, transformation from 3D data to $2 \mathrm{D}$ images is needed. One simplified way of reconstructing numerical Schlieren images is listed as follows: 
(1) Calculate the density gradient.

(2) Choose a direction as the light axis, which should be normal to the Schlieren image plane. Another direction is chosen as edge axis, which should be parallel to the Schlieren image plane. In this paper, the $\mathrm{z}$ axis is chosen as the light axis and the y axis as the edge axis. Then calculate the field $\nabla \rho \cdot \boldsymbol{y}$.

(3) Integrate the field $\nabla \rho \cdot \boldsymbol{y}$ along the $\mathrm{z}$ direction.

\section{Results and Discussion}

\subsection{Pre-ignition Flow and Mixture Field}

The pre-ignition nonreacting flow field is analysed first. The simulated cold flow velocity field and experimental Schlieren images are compared in Fig. 4 Qualitatively similar patterns can be found between simulation and experimen- 


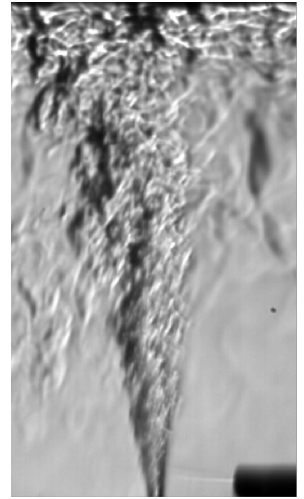

(a)



(b)

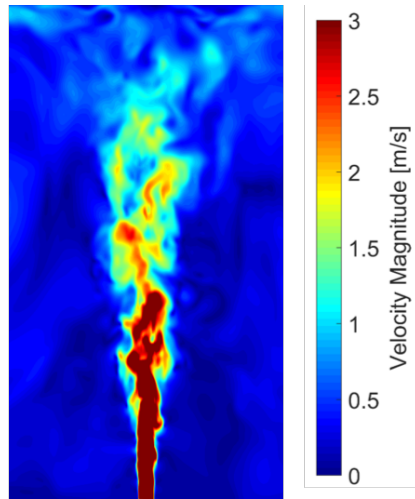

(c)

Figure 4: The pre-ignition flow field: (a) experimental Schlieren picture (b) numerical Schlieren picture (c) numerical velocity contours (at central plane)

to reaching the impingement plate, is different for the two mechanisms. The overall flame development time for s6r2 $(80 \mathrm{~ms})$ is significantly shorter than that of s22r66 $(110 \mathrm{~ms})$. In experimental results, the reference time is $112 \mathrm{~ms}$ which 225 is closer to the s22r66 result. From previous discussions, the s6r2 mechanism tends to over-estimate the reaction rate in the fuel-rich branch. This is especially clear on the fuel-rich side. In the same areas around the central propane jet for s22r66 simulation, little reaction occurs. As a result, the flame structures are very different: s22r66 predicts an open "tulip" structure while s6r2 gives an enclosed structure. This is confirmed by Fig. 6, which shows the flame structures defined by the calculated heat release rate. When viewed from the top, the s22r66 mechanism predicts a ring-like flame structure, with apparently no flame in the jet central region. The same ring-like flame structure is obtained by the flame imaging technique in the experiment. In the experimental image, the blue colours indicate intensive reaction zones while the orange colours correspond to post-combustion zones. It should also be noted that the isolated orange spot in the lower part of the image is the ignition source rather than part of the flame. In contrast, the simplified mechanism s6r2 predicts a significantly larger area of reactions overall, while the jet central region, in particular, has intense reactions. 


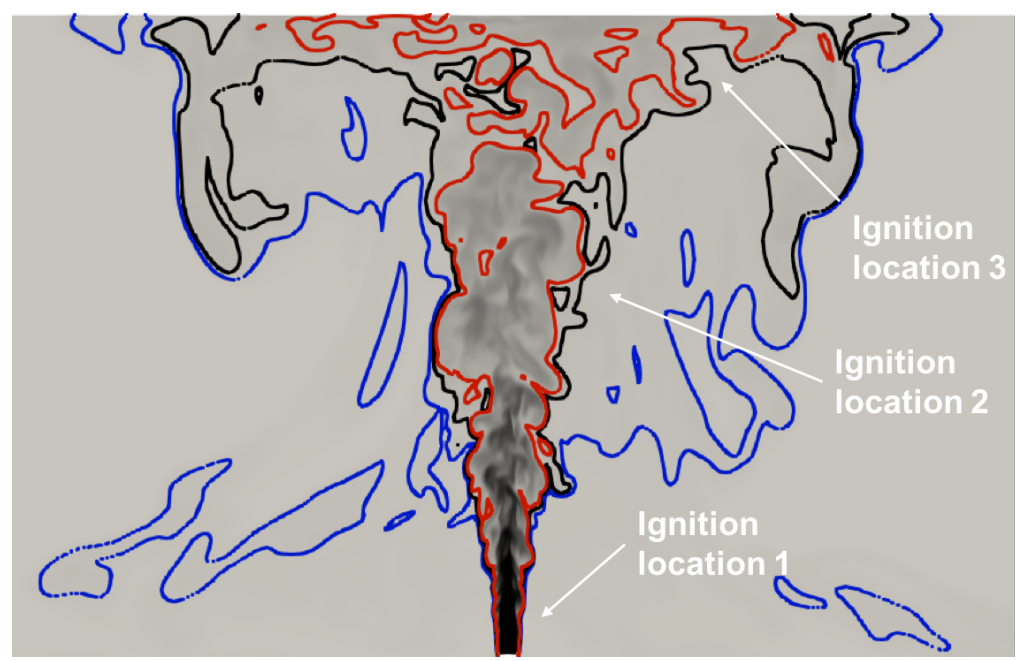

Figure 5: Pre-ignition mixture fraction contours and ignition points from simulation. Contour lines refer to $Z=0.5 Z_{\text {st }}$ (blue), $Z=Z_{s t}$ (black) and $Z=2 Z_{\text {st }}$ (red)

These results confirm that reaction mechanisms have strong influences on the predicted flame both quantitatively and qualitatively. The newly developed s22r66 mechanism predicts correct behaviours in both laminar and turbulent flames, and therefore will be used in the following sections.

\subsection{Ignition and flame development}

Using the validated mechanism with 22 species 66 steps (s22r66), three ignition cases corresponding to the experiments are simulated using LES with the DTF model. Numerical Schlieren images for the three cases at different time instants are shown in Fig. 7) The different time sequences are selected to match the similar stages of combustion in the experiments [36]. Three stages during flame development are chosen to compare with experiments. The overall flame propagation process matches the experiments and the development time is similar (110 ms to $112 \mathrm{~ms}$ ).

In Case 1, the propane/air mixture is ignited near the nozzle exit. The flame exhibits features of a jet flame until it reaches the near impingement region, where it starts to expand horizontally. From the corresponding temperature 


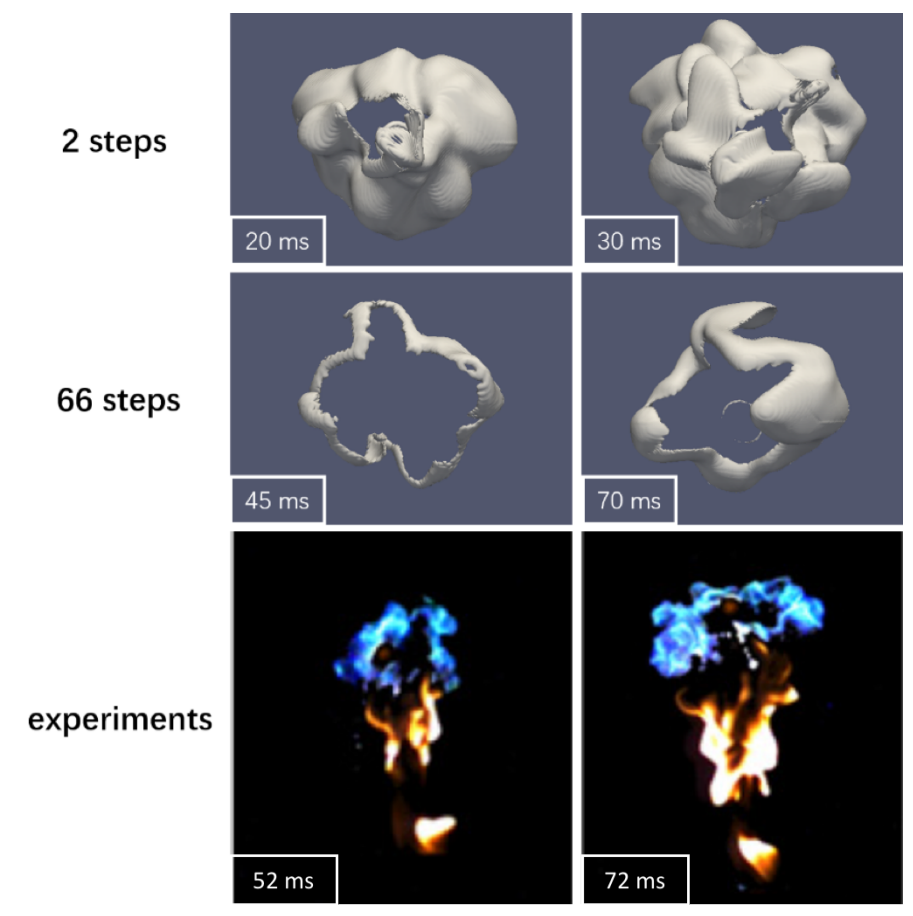

Figure 6: Flame structures obtained by propane mechanisms with 22 species 66 steps (midpanel) and 6 species 2 steps (top panel) for ignition Case 1, in comparison with experimental flame images.

contours in Fig. 8 (top panel), it can be seen that the high temperature region stays around the stoichiometric mixture fraction lines/surfaces. The flame in Case 1 appears to be predominantly a diffusion flame, but detailed analysis in the following section would show existence of a premixed combustion mode as well.

In Case 2, the propane/air mixture is ignited in a region where there is a considerable degree of pre-mixing. The flame develops along the stoichiometric line/surface as a diffusion flame like Case 1. The difference from Case 1 is that the initial flame in Case 2 never develops into a jet diffusion flame (Fig. 8). Instead, the flame also propagates towards the fuel-lean and fuel-rich regions away from the stoichiometric line/surface. The mode of reaction is more like a premixed flame rather than a non-premixed flame, which becomes clearer by 


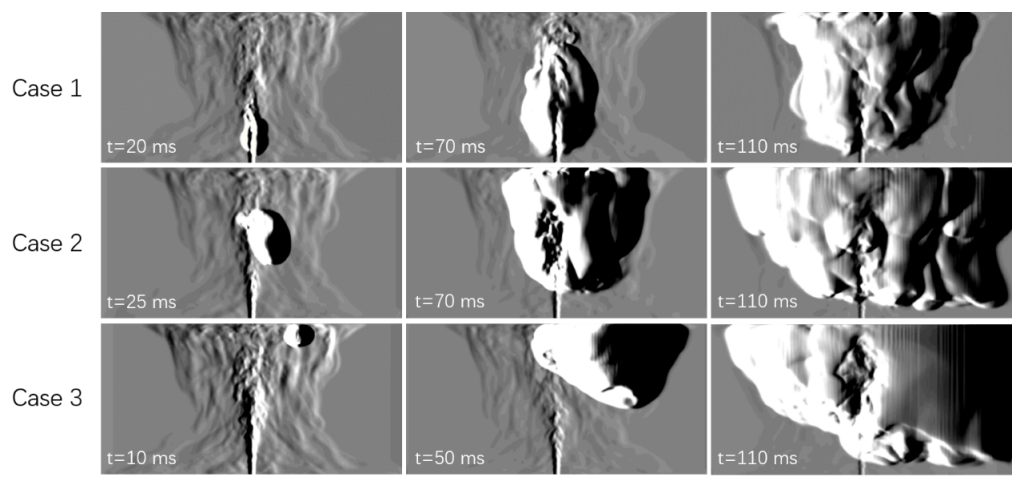

Figure 7: Numerical Schlieren images of flame development after ignition from LES with the DTF model and s22r66 propane mechanism in Cases 1, 2 and 3.

the time $\mathrm{t}=70 \mathrm{~ms}$. The existence of both non-premixed and premixed flames quickly spreads the flame in both the axial and lateral directions. By the time $\mathrm{t}=70 \mathrm{~ms}$, the flame in Case 2 already reaches the impingement plate while the flame in Case 1 is still far away from the plate. By the time $t=110 \mathrm{~ms}$, the overall size of the flame in Case 2 is almost twice that in Case 1.

In Case 3, the propane/air mixture is ignited in a region near the impingement plate where there is a significant degree of pre-mixing. The ignition spot develops into a spherical flame (at $\mathrm{t}=10 \mathrm{~ms}$ ), typical of an ignition in premixed combustion. Due to wall confinement, the flame expands significantly in the lateral direction towards the surrounding air. Interestingly, the stoichiometric line/surface also moves quickly with the expanding flame $(\mathrm{t}=50 \mathrm{~ms})$, suggesting that entrainment (of air into propane) and mixing is fast enough to keep up with the flame propagation in the lateral direction. At time $\mathrm{t}=110 \mathrm{~ms}$, the developed flame in Case 3 is of comparable size as that in Case 2, although detailed flame structures are different.

The integral heat release rates for the above three cases are compared in Fig. 9. As the DTF model is applied in the simulation, the integral heat release rate is calculated as:

$$
d h_{\text {integral }}=\int_{V} \frac{d h}{F} d V
$$



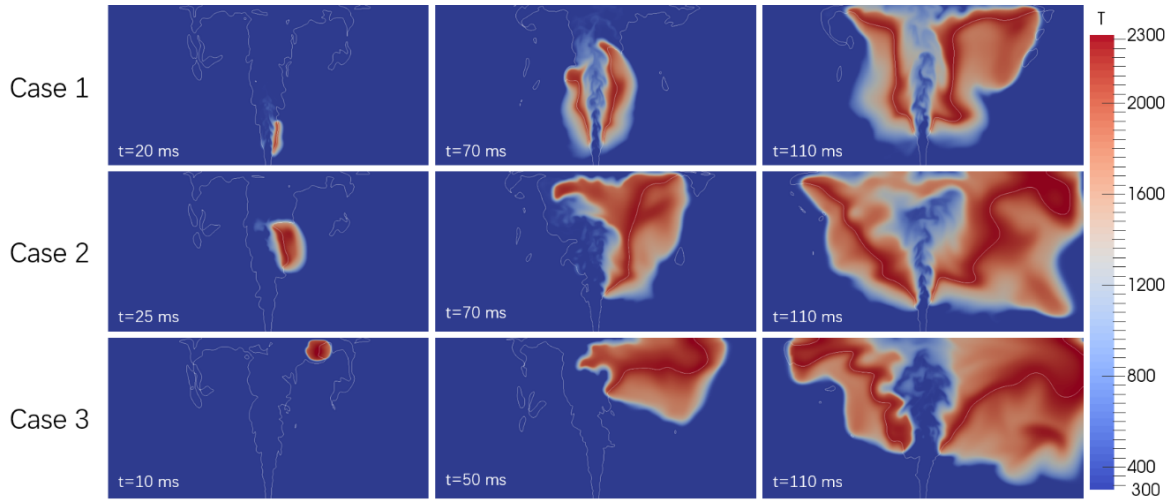

Figure 8: Temperature variation with time for the three ignition cases, where the white lines represent the stoichiometric mixture fraction $\mathrm{Zst}=0.0602$.

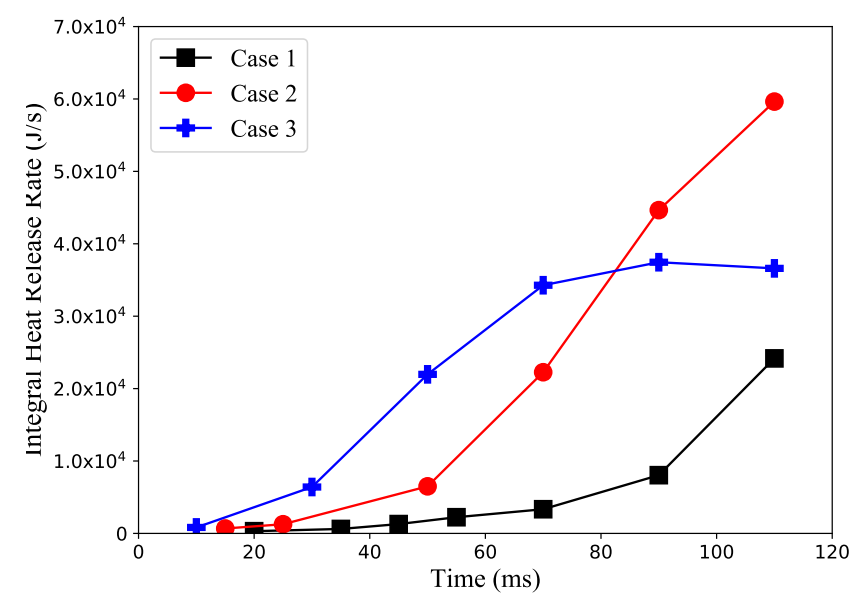

Figure 9: Integral heat release rates for different ignition cases.

$d h / F$ is the true sensible enthalpy source term in the transport equation Eq. 2 $\mathrm{dh}$ refers to the instantaneous heat release rate (HRR), F refers to the dynamic

thickening factor. Among the three cases, the growth rate of the integral HRR with time in Case 1 is the lowest for most of the time, reflecting the initially dominant diffusion flame feature. Only in the final stage ( $\mathrm{t}>90 \mathrm{~ms}$ ), its growth rate of the integral HRR picks up strongly, due to 1 onset of a turbulent 
premixed flame. Case 3 has the highest growth rate in integral HRR at the impinging wall.

Since chemical reaction itself doesn't change the mixture fraction, the differences in the three cases are mainly caused by velocity field. The ignition process triggers the changes of local density field, and thus the velocity field is When the velocity is normal to the flame front (defined by heat release rate) and flow outwards, it can be regarded as expansion mode. In Case 2 and Case 3 , the expansion mode can be found. Compared with Case 2, in Case 3, the 
vertical expansion is limited by the impinging wall so the horizontal movement is stronger. In Case 1, this mode is not very clear. Because of the expansion effect, unburned mixture will be carried to further location (away from the jet). It explains the difference in mixture fraction distribution for the three cases.
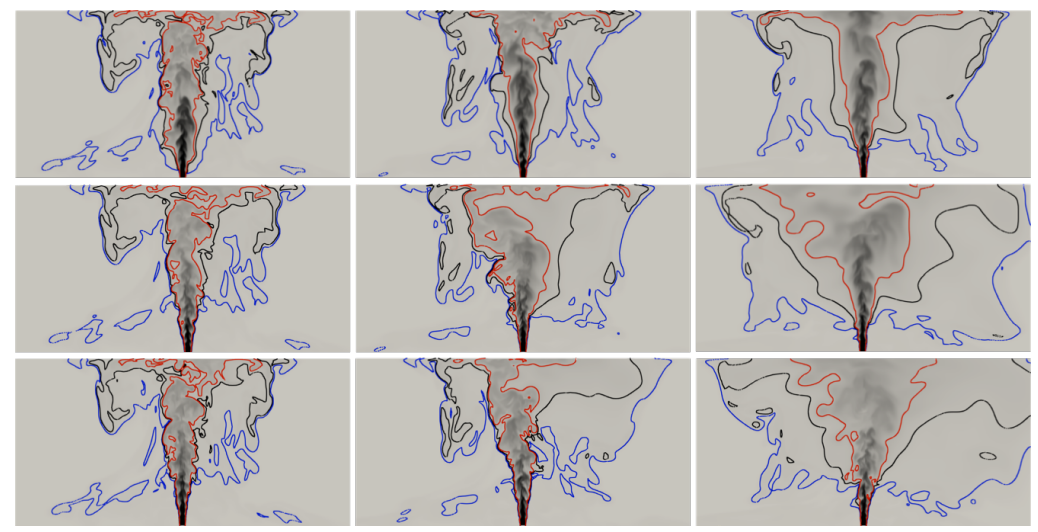

Figure 10: Mixture fraction contours for all three cases at different time instants. Top: Case 1 at 20, 70, $110 \mathrm{~ms}$; Middle: Case 2 at 15, $70110 \mathrm{~ms}$; Bottom: Case 3 at 10, 50, $110 \mathrm{~ms}$. Contour lines refer to $Z=0.5 Z_{\text {st }}$ (blue), $Z=Z_{\text {st }}$ (black) and $Z=2 Z_{\text {st }}$ (red)

\subsection{Premixed/Non-premixed Analysis}

To analyze flame modes in different ignition cases, Chemical Explosive Mode Analysis (CEMA) is used and a modifed flame indicator is selected for comparison. CEMA, developed by Lu et al 62 can be used to analyse the combustion mode based on the evolution of species and temperature. Basic equations are in Eq. 8,9, $\boldsymbol{y}$ is a list consisting of species and temperature: $\boldsymbol{y}=\left[y_{1}, y_{2}, \ldots, y_{n}, T\right]$. $\boldsymbol{J}$ is Jacobian matrix of function $g$.

$$
\begin{gathered}
\frac{d \boldsymbol{y}}{d t}=\boldsymbol{g}(\boldsymbol{y}) \\
\frac{d \boldsymbol{g}}{d t}=\boldsymbol{J} \cdot \boldsymbol{g}(\boldsymbol{y})
\end{gathered}
$$

By calculating the eigenvalue of the matrix $\boldsymbol{J}$, and taking the non-conservative term with the largest real part as $\lambda_{e}$, a criterion for determining the flame mode 

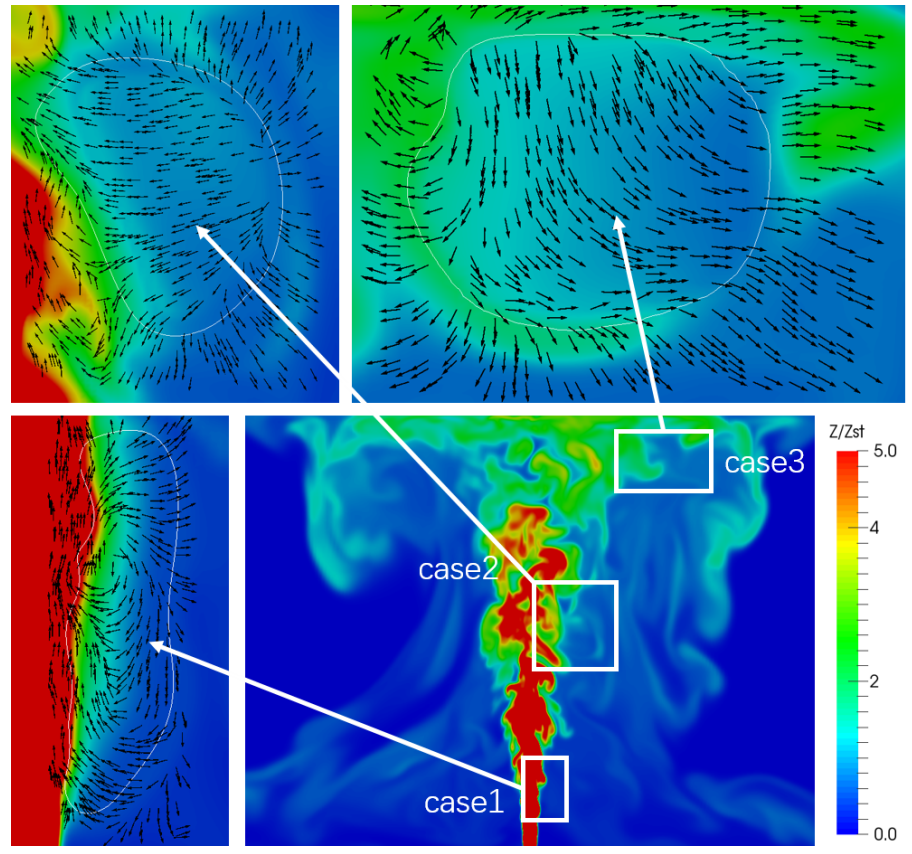

Figure 11: Flow fields corresponding to three different ignition locations. Expansion effect can be seen from the velocity vector field and the effect increases with the decreasing distance to the impinging surface.

is obtained as:

$$
\gamma_{e}=\operatorname{sign}\left(\lambda_{e}\right) \cdot \log _{10}\left(1+\left|\operatorname{Re}\left(\lambda_{e}\right)\right|\right)
$$

$\gamma_{e}$ is used to distinguish premixed and non-premixed flame regions. In the reacting region, when $\gamma_{e}>0$, it can be regarded as premixed flame; otherwise it would be regarded as non-premixed flame.

Besides CEMA, a modified flame indicator (FI) 62 is also used (Eq. 11 , 12). In the conventional flame indicator (Eq. 11) by Yamashital 63, when concentration of selected species (e.g. fuel or air) is near zero, the sign of the flame indicator is meaningless. By introducing a cut off reference value, the near-zero value could be filtered out.

$$
F I_{0}=\nabla Y_{\mathrm{C}_{3} \mathrm{H}_{8}} \cdot \nabla Y_{\mathrm{O}_{2}}
$$




$$
F I=\operatorname{sign}\left(F I_{0}\right) \times \log _{10}\left(1+\left|F I_{0}\right|\right)
$$

Before further discussing the combustion modes during flame propagation, comparisons are made between CEMA and FI results (Fig. 12,13. Both CEMA and FI results show that the region within $d h=10^{8} \mathrm{~J} / \mathrm{s}$ (thick dot line) to be mainly premixed; here we name it 'high-heat-release premixed flame'. But the region of $10^{7} \mathrm{~J} / \mathrm{s}<d h<10^{8} \mathrm{~J} / \mathrm{s}$ (between thin and thick dot line) in CEMA result is mainly non-premixed flame while the FI result is neither premixed nor non-premixed flame $(F I=0)$. The contradiction happens in detailed chemistry where the fuel specie has already been decomposed into smaller species while the reaction is still proceeding. In this simulation, $\mathrm{C}_{3} \mathrm{H}_{8}$ is decomposed into $\mathrm{C}_{1}$ and $\mathrm{C}_{2}$ in a relatively short time, and FI would show near zero value in the region. However, $\mathrm{C}_{1}$ and $\mathrm{C}_{2}$ will continue reacting with oxidiser to further release heat. As multiple fuels exist in the flame region but only one is considered in the gradient calculation, information of decomposed fuels' combustion could be lost. Therefore, we may conclude that CEMA is more general for handling detailed chemistry.

In the early stage after ignition of Case 1 (Fig. 12), it can be seen from the CEMA result that within the reaction zone, the premixed region is located on the outer side of the flame but the inner side is mostly in non-premixed mode.

${ }_{345}$ When the flame propagates to the wall (Fig. 13), the near wall reaction zone is shown to be mainly premixed.

Similar stages of Case 2 and Case 3 are shown in Fig. 14. In Case 2, premixed mode can also be found in the inner side, which is different from the flame in cCase 1 . The heat release rate in this inner premixed zone is relatively low compared with the outer premixed zone due to local fuel-rich mixture (can be named as 'low-heat-release premixed flame'). The flame after ignition in Case 2 consists of fuel-rich premixed flame (inner), diffusion flame (middle) and fuel lean premixed flame (outer). Moreover, the diffusion flame has an intensively reacting zone and a weakly reacting zone. In Case 3 , the two heat release rate 

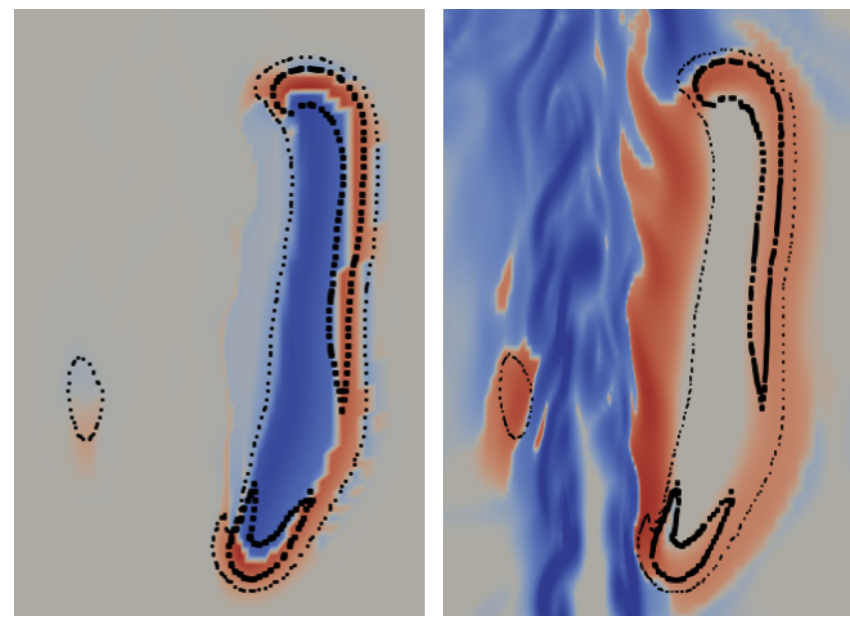

Figure 12: Result of Case 1 at $20 \mathrm{~ms}$. left: CEMA result, red and blue refer to explosive and non-explosive modes; right: Flame indicator result, red and blue refer to premixed and non-premxied modes. Black contour lines represent heat release rate of $10^{7} \mathrm{~J} / \mathrm{s}$ (thin) and $10^{8} \mathrm{~J} / \mathrm{s}$ (thick)
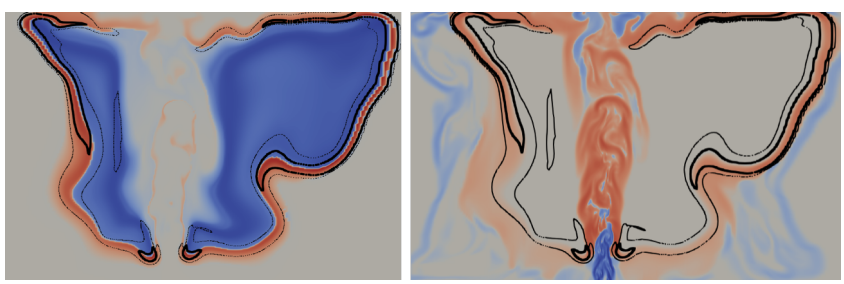

Figure 13: Result of Case 1 at $110 \mathrm{~ms}$. left: CEMA result, red and blue refer to explosive and non-explosive modes; right: Flame indicator result, red and blue refer to premixed and non-premxied mode. Contour black contour lines represent heat release rate of $10^{7} \mathrm{~J} / \mathrm{s}$ (thin) and $10^{8} \mathrm{~J} / \mathrm{s}$ (thick)

lines are highly overlapped, and the whole spherical flame zone is surrounded by high-heat-release premixed flames.

From Case 1 to Case 3, as the ignition location moves closer to the impinging wall, the early stage combustion after ignition becomes increasingly dominated by high-heat-release premixed flame. When comparing the CEMA result together with velocity vector field in Fig. 11, it can be found that the gas expansion discussed in previous section, is due to the high-heat-release premxied 

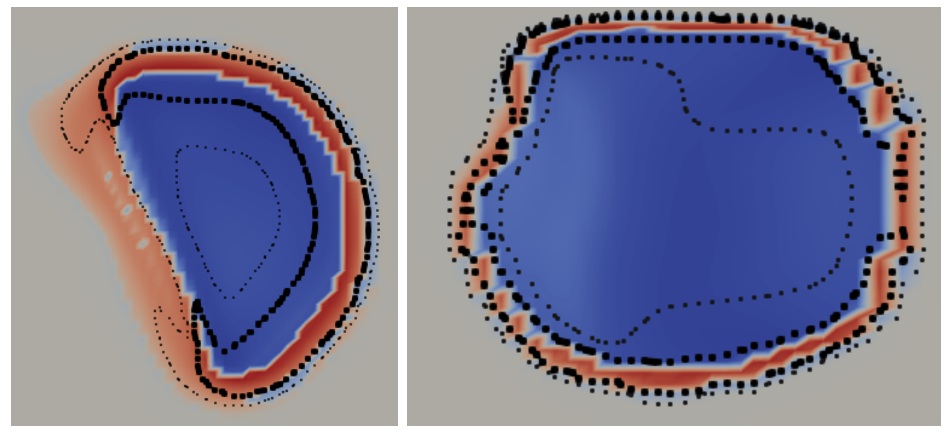

Figure 14: CEMA results of Case 2 at $15 \mathrm{~ms}$ (left) and Case 3 at $10 \mathrm{~ms}$ (right). Black contour lines represent heat release rate of $10^{7} \mathrm{~J} / \mathrm{s}$ (thin) and $10^{8} \mathrm{~J} / \mathrm{s}$ (thick)

flame. The gas expansion, however, is constrained by the presence of the wall, as is the case in the top region of Case 3 where the gas expansion is mostly in horizontal direction. In the fuel-rich premixed flame and diffusion flame zones, gas expansion is less pronounced.

\section{Conclusion}

Large eddy simulation incorporating a dynamic thickened flame (DTF) model for realistic chemistry has been developed to study the dynamic processes of ignition and flame development in turbulent impinging flames. A new and efficient chemical mechanism for propane, with 22 species 66 steps, has been demonstrated to provide correct predictions for both fuel-rich and fuel-lean conditions. The developed LES formulation has reproduced the ignition process and turbulent impinging flames under three ignition conditions corresponding to experiments.

375 The flame indicator (FI) and chemical explosive mode analysis (CEMA) have been adopted to distinguish local premixed/non-premixed combustion modes. CEMA shows advantages over the FI method for capturing non-premixed flames, as FI only considers one fuel species multiple chemical species exist in realistic chemistry. Both premixed and non-premixed combustion modes exist in the turbulent impinging flames, even when a jet flame is specified at the 
inlet. Moreover, the extent and distribution of premixed/non-premixed flame modes, are different for the three selected ignition locations relative to the wall. The thermal expansion triggered by ignition in premixed flame leads to different flow and mixing processes, which in turn affects the subsequent flame development. The variation of the overall heat release with time is different for the three ignition locations, reflecting different contributions from the premixed and diffusion flames, respectively. The study advances our understanding of turbulent impinging flames and ignition of premixed,non-premixed and partially premixed flames.

\section{Acknowledgement}

Support from the Major Programme of the National Science Foundation of China (Grant No. 91441120) and the Center for Combustion Energy at Tsinghua University is gratefully acknowledged. Profs Luo and Wang are grateful for the support under the project "Experimental and numerical investigation on impinging reacting flow and multiphase flow phenomena", funded by The Royal Society - Natural Science Foundation of China International Exchanges Scheme (Grant Nos. IE150647 and 5151101371). Further support from the EPSRC projects "UK Consortium on Mesoscale Engineering Sciences (UKCOMES)" (Grant Nos. EP/L00030X/1 and EP/R029598/1) is also acknowledged.

\section{References}

[1] Y. M. Chung, K. H. Luo, Unsteady heat transfer analysis of an impinging jet, Transactions-American Society of Mechanical Engineers Journal of Heat Transfer 124 (6) (2002) 1039-1048. doi:10.1115/1.1469522.

[2] Y. Chung, K. Luo, N. Sandham, Numerical study of momentum and heat transfer in unsteady impinging jets, International Journal of Heat and Fluid Flow 23 (5) (2002) 592-600. doi:10.1016/S0142-727X(02) 00155-8. 
[3] X. Jiang, K. Luo, L. de Goey, R. Bastiaans, J. van Oijen, Swirling and impinging effects in an annular nonpremixed jet flame, Flow, Turbulence and Combustion 86 (1) (2011) 63-88. doi:10.1007/s10494-010-9287-y.

[4] K. R. Dinesh, X. Jiang, J. Van Oijen, Numerical simulation of hydrogen impinging jet flame using flamelet generated manifold reduction, international journal of hydrogen energy 37 (5) (2012) 4502-4515. doi: $10.1016 / j . i j h y d e n e .2011 .11 .144$

[5] J. Jiang, T. Wu, J. Yi, X. Jiang, A study of instabilities in hydrogenair impinging jet flames using two and three dimensional direct numerical

घ simulations, Energy Procedia 66 (2015) 325-328. doi:10.1016/j .egypro. 2015.02 .076

[6] X. Jiang, H. Zhao, K. H. Luo, Direct numerical simulation of a nonpremixed impinging jet flame, Journal of Heat Transfer 129 (8) (2007) 951-957. doi:10.1115/1.2737480.

[7] S.-S. Hou, Y.-C. Ko, Effects of heating height on flame appearance, temperature field and efficiency of an impinging laminar jet flame used in domestic gas stoves, Energy conversion and management 45 (9) (2004) 1583-1595. doi:10.1016/j.enconman.2003.09.016.

${ }_{425}$ [8] H. Zhen, Z. Wei, C. Leung, C. Cheung, Z. Huang, Emission of impinging biogas/air premixed flame with hydrogen enrichment, international journal of hydrogen energy 41 (3) (2016) 2087-2095. doi:10.1016/j.ijhydene. 2015.11.037.

[9] Y.-C. Chien, D. Escofet-Martin, D. Dunn-Rankin, Co emission from an impinging non-premixed flame, Combustion and Flame 174 (2016) 16-24. doi:10.1016/j.combustflame.2016.09.004

[10] L. Dong, C. Cheung, C. Leung, Heat transfer characteristics of an impinging inverse diffusion flame jet-part i: Free flame structure, Inter- 
national journal of heat and mass transfer 50 (25) (2007) 5108-5123.

[11] L. Dong, C. Cheung, C. Leung, Heat transfer characteristics of an impinging inverse diffusion flame jet. part ii: Impinging flame structure and impingement heat transfer, International journal of heat and mass transfer 50 (25) (2007) 5124-5138. doi:10.1016/j.ijheatmasstransfer.2007.07.017.

[12] L. Dong, C. Cheung, C. Leung, Heat transfer optimization of an impinging port-array inverse diffusion flame jet, Energy 49 (2013) 182-192. doi: $10.1016 / \mathrm{j}$.energy .2012.10.041.

[13] S. Tuttle, B. Webb, M. McQuay, Convective heat transfer from a partially premixed impinging flame jet. part i: Time-averaged results, International

445 journal of heat and mass transfer 48 (7) (2005) 1236-1251. doi:10.1016/ j.ijheatmasstransfer.2004.10.027.

[14] S. Tuttle, B. Webb, M. McQuay, Convective heat transfer from a partially premixed impinging flame jet. part ii: Time-resolved results, International

口 journal of heat and mass transfer 48 (7) (2005) 1252-1266. doi:10.1016/ j.ijheatmasstransfer.2004.10.028.

[15] V. Terekhov, S. Kalinina, K. Sharov, An experimental investigation of flow structure and heat transfer in an impinging annular jet, Interna-

n tional Communications in Heat and Mass Transfer 79 (2016) 89-97. doi: 10.1016/j.icheatmasstransfer.2016.10.011.

[16] M. Morad, A. Momeni, E. E. Fordoei, M. Ashjaee, Experimental and numerical study on heat transfer characteristics for methane/air flame impinging on a flat surface, International Journal of Thermal Sciences 110 (2016) 229-240. doi:10.1016/j.ijthermalsci.2016.07.005.

[17] K. R. Dinesh, X. Jiang, J. Van Oijen, Hydrogen-enriched non-premixed 460 jet flames: compositional structures with near-wall effects, International 
Journal of Hydrogen Energy 38 (12) (2013) 5150-5164. doi:10.1016/j. ijhydene.2013.02.041.

[18] D. M. Martinez, X. Jiang, C. Moulinec, D. Emerson, Numerical investigation of the effects of fuel variability on the dynamics of syngas impinging jet flames, Fuel 103 (2013) 646-662. doi:10.1016/j.fuel.2012.06.025

[19] P. Pantangi, A. Sadiki, J. Janicka, M. Mann, A. Dreizler, Les of premixed methane flame impinging on the wall using non-adiabatic flamelet generated manifold (fgm) approach, Flow, Turbulence and Combustion 92 (4) (2014) 805-836. doi:10.1007/s10494-013-9526-0.

${ }_{470}$ [20] D. Mira, M. Zavala, M. Avila, H. Owen, J. C. Cajas, M. Vázquez, G. Houzeaux, Heat transfer effects on a fully premixed methane imping[ ing flame, Flow, Turbulence and Combustion (2016) 1-23doi:10.1007/ s10494-015-9694-1.

[21] D. M. Martinez, X. Jiang, Numerical investigations of a hydrogen impinging flame with different finite-rate chemical kinetic mechanisms, Fuel 109 (2013) 285-296. doi:10.1016/j.fuel.2012.12.026.

[22] Z. Qin, V. V. Lissianski, H. Yang, W. C. Gardiner, S. G. Davis, H. Wang, Combustion chemistry of propane: a case study of detailed reaction mechanism optimization, Proceedings of the Combustion Institute 28 (2) (2000) 1663-1669. doi:10.1016/S0082-0784(00)80565-2.

[23] S. Gallagher, H. Curran, W. Metcalfe, D. Healy, J. Simmie, G. Bourque, A rapid compression machine study of the oxidation of propane in the negative temperature coefficient regime, Combustion and Flame 153 (1-2) (2008) 316-333. doi:10.1016/j.combustflame.2007.09.004.

${ }_{485}$ [24] E. Ranzi, C. Cavallotti, A. Cuoci, A. Frassoldati, M. Pelucchi, T. Faravelli, New reaction classes in the kinetic modeling of low temperature oxidation 口 of n-alkanes, Combustion and flame 162 (5) (2015) 1679-1691. doi:10. $1016 / j$.combustflame.2014.11.030 
[25] S. S. Merchant, C. F. Goldsmith, A. G. Vandeputte, M. P. Burke, S. J. Klippenstein, W. H. Green, Understanding low-temperature first-stage ignition delay: Propane, Combustion and Flame 162 (10) (2015) 3658-3673. doi:10.1016/j.combustflame.2015.07.005

[26] X. Shi, J.-Y. Chen, Y. Chen, Laminar flame speeds of stratified methane, propane, and n-heptane flames, Combustion and Flame 176 (2017) 38-47. doi:10.1016/j.combustflame.2016.10.018.

[27] J. C. Prince, C. Treviño, F. A. Williams, A reduced reaction mechanism for the combustion of n-butane, Combustion and Flame 175 (2017) 27-33. doi:10.1016/j.combustflame.2016.06.033

[28] K. C. Lin, C.-T. Chiu, A compact skeletal mechanism of propane towards applications from ntc-affected ignition predictions to cfd-modeled diffusion

【 flames: Comparisons with experiments, Fuel 203 (2017) 102-112. doi: $10.1016 / \mathrm{j}$. fuel.2017.04.064.

[29] E. Jithin, V. R. Kishore, R. J. Varghese, Three-dimensional simulations of steady perforated-plate stabilized propane-air premixed flames, Energy \& Fuels 28 (8) (2014) 5415-5425. doi:10.1021/ef401903y.

[30] L. Esclapez, E. Riber, B. Cuenot, Ignition probability of a partially premixed burner using les, Proceedings of the Combustion Institute 35 (3) (2015) 3133-3141. doi:10.1016/j.proci.2014.07.040

[31] G. Lacaze, E. Richardson, T. Poinsot, Large eddy simulation of spark ignition in a turbulent methane jet, Combustion and Flame 156 (10) (2009) 1993-2009. doi:10.1016/j.combustflame.2009.05.006

[32] W. Jones, V. Prasad, Les-pdf simulation of a spark ignited turbulent methane jet, Proceedings of the Combustion Institute 33 (1) (2011) 13551363. doi:10.1016/j.proci.2010.06.076 
[33] T. Foat, K. Yap, Y. Zhang, The visualization and mapping of turbulent premixed impinging flames, Combustion and flame 125 (1) (2001) 839-851. doi:10.1016/S0010-2180(00)00238-8.

[34] D. Durox, T. Schuller, S. Gandel, Self-induced instability of a premixed jet flame impinging on a plate, Proceedings of the Combustion Institute 29 (1) (2002) 69-75. doi:10.1016/S1540-7489(02)80013-X

[35] H. W. Huang, J. Yang, Q. Wang, Y. Zhang, Variation of hydrocarbon compositions and ignition locations on the radiative flame initiation characteristics through multi-dimensional dfcd incorporated image analysis, Fuel 103 (2013) 334-346. doi:10.1016/j.fuel.2012.04.046. imaging techniques, Fuel 108 (2013) 177-183. doi:10.1016/j.fuel.2013. 01.048

[37] T. Butler, P. O'rourke, A numerical method for two dimensional unsteady reacting flows, in: Symposium (International) on Combustion, Vol. 16, Elsevier, 1977, pp. 1503-1515. doi:10.1016/S0082-0784(77)80432-3.

[38] P. O'Rourke, F. Bracco, Two scaling transformations for the numerical computation of multidimensional unsteady laminar flames, Journal of Com-

п) putational Physics 33 (2) (1979) 185-203. doi:10.1016/0021-9991(79) 90015-9

[39] D. Veynante, T. Poinsot, Large eddy simulation of combustion instabilities in turbulent premixed burners, Annual Research Briefs (1997) 253-274.

[40] O. Colin, F. Ducros, D. Veynante, T. Poinsot, A thickened flame model for large eddy simulations of turbulent premixed combustion, Physics of Fluids 12 (7) (2000) 1843-1863. doi:10.1063/1.870436.

[41] F. Proch, A. M. Kempf, Numerical analysis of the cambridge stratified flame series using artificial thickened flame les with tabulated premixed 
flame chemistry, Combustion and Flame 161 (10) (2014) 2627-2646. doi: $10.1016 / j$.combustflame.2014.04.010

[47] J.-P. Legier, T. Poinsot, D. Veynante, Dynamically thickened flame les 565

[48] G. Kuenne, A. Ketelheun, J. Janicka, Les modeling of premixed combustion using a thickened flame approach coupled with fgm tabulated chem口

[42] A. De, S. Acharya, Large eddy simulation of premixed combustion with a thickened-flame approach, Journal of Engineering for Gas Turbines and Power 131 (6) (2009) 061501. doi:10.1115/1.3094021.

[43] F. Hernández-Pérez, F. Yuen, C. Groth, Ö. Gülder, Les of a laboratoryscale turbulent premixed bunsen flame using fsd, pcm-fpi and thickened flame models, Proceedings of the Combustion Institute 33 (1) (2011) 13651371. doi:10.1016/j.proci.2010.06.010

[44] S. Emami, K. Mazaheri, A. Shamooni, Y. Mahmoudi, Les of flame acceleration and ddt in hydrogen-air mixture using artificially thickened flame approach and detailed chemical kinetics, international journal of hydrogen energy 40 (23) (2015) 7395-7408. doi:10.1016/j.ijhydene.2015.03.165.

[45] F. Charlette, C. Meneveau, D. Veynante, A power-law flame wrinkling model for les of premixed turbulent combustion part i: non-dynamic formulation and initial tests, Combustion and Flame 131 (1) (2002) 159-180. doi:10.1016/S0010-2180(02)00400-5

[46] F. Charlette, C. Meneveau, D. Veynante, A power-law flame wrinkling model for les of premixed turbulent combustion part ii: dynamic formulation, Combustion and Flame 131 (1) (2002) 181-197. doi:10.1016/ S0010-2180(02)00401-7. model for premixed and non-premixed turbulent combustion, in: Proc. of the summer program, 2000, pp. 157-168.

istry, Combustion and Flame 158 (9) (2011) 1750-1767. doi:10.1016/j. combustflame.2011.01.005 
[49] P. Wang, J. Fröhlich, U. Maas, Z.-x. He, C.-j. Wang, A detailed comparison of two sub-grid scale combustion models via large eddy simulation of the preccinsta gas turbine model combustor, Combustion and Flame 164 (2016) 329-345. doi:10.1016/j.combustflame.2015.11.031.

[55] A. Buekens, Combustion: Physical and chemical fundamentals, modeling and simulation, experiments, pollutant formation, International Journal of Environment \& Pollution 17 (3) (2002) 291-291.

[56] K. Kumar, G. Mittal, C.-J. Sung, C. K. Law, An experimental investigation of ethylene/o 2/diluent mixtures: laminar flame speeds with preheat and 
ignition delays at high pressures, Combustion and Flame 153 (3) (2008)

343-354. doi:10.1016/j.combustflame.2007.11.012.

[57] J. Li, Z. Zhao, A. Kazakov, M. Chaos, F. L. Dryer, J. J. Scire, A comprehensive kinetic mechanism for co, ch2o, and ch3oh combustion, International Journal of Chemical Kinetics 39 (3) (2007) 109-136. doi: $10.1002 /$ kin. 20218

[58] C. K. Westbrook, F. L. Dryer, Simplified reaction mechanisms for the oxidation of hydrocarbon fuels in flames, Combustion science and technology 27 (1-2) (1981) 31-43. doi:10.1080/00102208108946970.

[59] C. Jiménez, B. Cuenot, T. Poinsot, D. Haworth, Numerical simulation and modeling for lean stratified propane-air flames, Combustion and Flame 128 (1) (2002) 1-21. doi:10.1016/S0010-2180(01) 00328-5.

[60] N. Kornev, E. Hassel, Method of random spots for generation of synthetic inhomogeneous turbulent fields with prescribed autocorrelation functions, International Journal for Numerical Methods in Biomedical Engineering 23 (1) (2007) 35-43. doi:10.1002/cnm.880.

[61] F. Ducros, F. Nicoud, T. Poinsot, Wall-adapting local eddy-viscosity models for simulations in complex geometries (1998).

[62] T. Lu, C. S. Yoo, J. Chen, C. K. Law, Three-dimensional direct numerical simulation of a turbulent lifted hydrogen jet flame in heated coflow: a chemical explosive mode analysis, Journal of Fluid Mechanics 652 (2010) 45-64. doi:10.1017/S002211201000039X.

[63] H. Yamashita, M. Shimada, T. Takeno, A numerical study on flame stability at the transition point of jet diffusion flames, in: Symposium (International) on Combustion, Vol. 26, Elsevier, 1996, pp. 27-34. doi: 10.1016/S0082-0784(96)80196-2. 
Table 1: The mechanism s22r66 for propane combustion

\begin{tabular}{|c|c|c|c|c|}
\hline No. & Reaction & A & $\mathrm{n}$ & $\mathrm{E}(\mathrm{KJ} / \mathrm{mol})$ \\
\hline \multicolumn{5}{|c|}{ Reaction of $\mathrm{C}_{3}$} \\
\hline 1 & $\mathrm{C}_{3} \mathrm{H}_{8}+\mathrm{H}=\mathrm{C}_{3} \mathrm{H}_{7}+\mathrm{H}_{2}$ & $1.3 \times 10^{6}$ & 2.54 & 6756 \\
\hline 2 & $\mathrm{C}_{3} \mathrm{H}_{8}+\mathrm{O}=\mathrm{C}_{3} \mathrm{H}_{7}+\mathrm{OH}$ & $1.9 \times 10^{5}$ & 2.68 & 3716 \\
\hline 3 & $\mathrm{C}_{3} \mathrm{H}_{8}+\mathrm{OH}=\mathrm{C}_{3} \mathrm{H}_{7}+\mathrm{H}_{2} \mathrm{O}$ & $1.4 \times 10^{3}$ & 2.66 & 527 \\
\hline 4 & $\mathrm{C}_{3} \mathrm{H}_{8}+\mathrm{O}_{2}=\mathrm{C}_{3} \mathrm{H}_{7}+\mathrm{HO}_{2}$ & $4.0 \times 10^{13}$ & 0.0 & 50930 \\
\hline 5 & $\mathrm{C}_{3} \mathrm{H}_{8}+\mathrm{HO}_{2}=\mathrm{C}_{3} \mathrm{H}_{7}+\mathrm{H}_{2} \mathrm{O}_{2}$ & $4.76 \times 10^{5}$ & 2.55 & 16490 \\
\hline 6 & $\mathrm{C}_{2} \mathrm{H}_{4}+\mathrm{CH}_{3}=\mathrm{C}_{3} \mathrm{H}_{7}$ & $3.3 \times 10^{11}$ & 0.0 & 7700 \\
\hline \multicolumn{5}{|c|}{ Reaction of $\mathrm{C}_{2}$} \\
\hline 7 & $\mathrm{C}_{2} \mathrm{H}_{4}+\mathrm{H}=\mathrm{C}_{2} \mathrm{H}_{3}+\mathrm{H}_{2}$ & $5.07 \times 10^{7}$ & 1.9 & 12950 \\
\hline 8 & $\mathrm{C}_{2} \mathrm{H}_{4}+\mathrm{O}=\mathrm{C}_{2} \mathrm{H}_{3}+\mathrm{OH}$ & $1.51 \times 10^{7}$ & 1.9 & 3740 \\
\hline 9 & $\mathrm{C}_{2} \mathrm{H}_{4}+\mathrm{O}=\mathrm{CH}_{3}+\mathrm{HCO}$ & $1.92 \times 10^{7}$ & 1.83 & 220 \\
\hline 10 & $\mathrm{C}_{2} \mathrm{H}_{4}+\mathrm{OH}=\mathrm{C}_{2} \mathrm{H}_{3}+\mathrm{H}_{2} \mathrm{O}$ & $3.06 \times 10^{6}$ & 2.0 & 2500 \\
\hline 11 & $\mathrm{C}_{2} \mathrm{H}_{3}+\mathrm{M}=\mathrm{C}_{2} \mathrm{H}_{2}+\mathrm{H}+\mathrm{M}$ & $3.86 \times 10^{8}$ & 1.62 & 37048.2 \\
\hline 12 & $\mathrm{C}_{2} \mathrm{H}_{3}+\mathrm{H}=\mathrm{C}_{2} \mathrm{H}_{2}+\mathrm{H}_{2}$ & $9.0 \times 10^{13}$ & 0.0 & 0.0 \\
\hline 13 & $\mathrm{C}_{2} \mathrm{H}_{3}+\mathrm{OH}=\mathrm{C}_{2} \mathrm{H}_{2}+\mathrm{H}_{2} \mathrm{O}$ & $3.011 \times 10^{13}$ & 0.0 & 0.0 \\
\hline 14 & $\mathrm{C}_{2} \mathrm{H}_{3}+\mathrm{O}_{2}=\mathrm{HCO}+\mathrm{CH}_{2} \mathrm{O}$ & $4.6 \times 10^{16}$ & -1.39 & 1010 \\
\hline 15 & $\mathrm{C}_{2} \mathrm{H}_{2}+\mathrm{O}=\mathrm{HCCO}+\mathrm{H}$ & $1.632 \times 10^{7}$ & 2.0 & 1900 \\
\hline 16 & $\mathrm{C}_{2} \mathrm{H}_{2}+\mathrm{OH}=\mathrm{CH}_{3}+\mathrm{CO}$ & $4.83 \times 10^{-4}$ & 4.0 & -2000 \\
\hline 17 & $\mathrm{HCCO}+\mathrm{O}=\mathrm{H}+2 \mathrm{CO}$ & $1.0 \times 10^{14}$ & 0.0 & 0.0 \\
\hline 18 & $\mathrm{HCCO}+\mathrm{O}_{2}=\mathrm{OH}+2 \mathrm{CO}$ & $1.6 \times 10^{12}$ & 0.0 & 854 \\
\hline 19 & $\mathrm{HCCO}+\mathrm{HCCO}=\mathrm{C}_{2} \mathrm{H}_{2}+2 \mathrm{CO}$ & $1.0 \times 10^{13}$ & 0.0 & 0.0 \\
\hline \multicolumn{5}{|c|}{ Reaction of $\mathrm{C}_{1}$} \\
\hline 20 & $\mathrm{CH}_{4}+\mathrm{H}=\mathrm{CH}_{3}+\mathrm{H}_{2}$ & $6.6 \times 10^{8}$ & 1.62 & 10840 \\
\hline 21 & $\mathrm{CH}_{4}+\mathrm{O}=\mathrm{CH}_{3}+\mathrm{OH}$ & $1.02 \times 10^{9}$ & 1.5 & 8600 \\
\hline 22 & $\mathrm{CH}_{4}+\mathrm{OH}=\mathrm{CH}_{3}+\mathrm{H}_{2} \mathrm{O}$ & $1.0 \times 10^{8}$ & 1.6 & 3120 \\
\hline
\end{tabular}




\begin{tabular}{|c|c|c|c|c|}
\hline 23 & $\mathrm{CH}_{3}+\mathrm{O}=\mathrm{CH}_{2} \mathrm{O}+\mathrm{H}$ & $8.43 \times 10^{13}$ & 0.0 & 0.0 \\
\hline 24 & $\mathrm{CH}_{3}+\mathrm{O}_{2}=\mathrm{OH}+\mathrm{CH}_{2} \mathrm{O}$ & $3.6 \times 10^{10}$ & 0.0 & 8940 \\
\hline 25 & $\mathrm{CH}_{3}+\mathrm{H}_{2} \mathrm{O}_{2}=\mathrm{CH}_{4}+\mathrm{HO}_{2}$ & $2.45 \times 10^{4}$ & 2.47 & 5180 \\
\hline 26 & $\mathrm{CH}_{3}+\mathrm{HCCO}=\mathrm{C}_{2} \mathrm{H}_{4}+\mathrm{CO}$ & $5.0 \times 10^{13}$ & 0.0 & 0.0 \\
\hline 27 & $\mathrm{CH}_{3}+\mathrm{H}(+\mathrm{M})=\mathrm{CH}_{4}(+\mathrm{M})$ & $1.27 \times 10^{16}$ & -0.63 & 383 \\
\hline 28 & $\mathrm{CH}_{2} \mathrm{O}+\mathrm{H}=\mathrm{HCO}+\mathrm{H}_{2}$ & $2.3 \times 10^{10}$ & 1.05 & 3275 \\
\hline 29 & $\mathrm{CH}_{2} \mathrm{O}+\mathrm{O}=\mathrm{HCO}+\mathrm{OH}$ & $3.9 \times 10^{13}$ & 0.0 & 3540 \\
\hline 30 & $\mathrm{CH}_{2} \mathrm{O}+\mathrm{OH}=\mathrm{HCO}+\mathrm{H}_{2} \mathrm{O}$ & $3.43 \times 10^{9}$ & 1.18 & -447 \\
\hline 31 & $\mathrm{CH}_{2} \mathrm{O}+\mathrm{O}_{2}=\mathrm{HCO}+\mathrm{HO}_{2}$ & $1.0 \times 10^{14}$ & 0.0 & 40000 \\
\hline 32 & $\mathrm{CH}_{2} \mathrm{O}+\mathrm{HO}_{2}=\mathrm{HCO}+\mathrm{H}_{2} \mathrm{O}_{2}$ & $1.0 \times 10^{12}$ & 1.6 & 8000 \\
\hline 33 & $\mathrm{HCO}+\mathrm{O}=\mathrm{CO}+\mathrm{OH}$ & $3.0 \times 10^{13}$ & 0.0 & 0.0 \\
\hline 34 & $\mathrm{HCO}+\mathrm{O}=\mathrm{CO}_{2}+\mathrm{H}$ & $3.0 \times 10^{13}$ & 0.0 & 0.0 \\
\hline 35 & $\mathrm{HCO}+\mathrm{OH}=\mathrm{CO}+\mathrm{H}_{2} \mathrm{O}$ & $3.0 \times 10^{13}$ & 0.0 & 0.0 \\
\hline 36 & $\mathrm{HCO}+\mathrm{H}_{2} \mathrm{O}=\mathrm{CO}+\mathrm{H}+\mathrm{H}_{2} \mathrm{O}$ & $2.244 \times 10^{18}$ & -1.0 & 17000 \\
\hline 37 & $\mathrm{HCO}+\mathrm{O}_{2}=\mathrm{CO}+\mathrm{HO}_{2}$ & $1.204 \times 10^{10}$ & 0.807 & -727 \\
\hline 38 & $\mathrm{HCO}+\mathrm{M}=\mathrm{CO}+\mathrm{H}+\mathrm{M}$ & $1.87 \times 10^{17}$ & -1.0 & 17000 \\
\hline 39 & $\mathrm{CO}+\mathrm{H}_{2}+\mathrm{M}=\mathrm{CH}_{2} \mathrm{O}+\mathrm{M}$ & $4.3 \times 10^{7}$ & 1.5 & 79600 \\
\hline 40 & $\mathrm{HCO}+\mathrm{H}=\mathrm{CO}+\mathrm{H}_{2}$ & $1.2 \times 10^{14}$ & 0.0 & 0.0 \\
\hline 41 & $\mathrm{HCO}+\mathrm{H}(+\mathrm{M})=\mathrm{CH}_{2} \mathrm{O}(+\mathrm{M})$ & $1.09 \times 10^{12}$ & 0.48 & -260 \\
\hline \multicolumn{5}{|c|}{$\mathrm{H}_{2} / \mathrm{CO}$ reactions } \\
\hline 42 & $\mathrm{H}+\mathrm{O}_{2}=\mathrm{O}+\mathrm{OH}$ & $3.55 \times 10^{15}$ & -0.4 & 16599 \\
\hline 43 & $\mathrm{O}+\mathrm{H}_{2}=\mathrm{H}+\mathrm{OH}$ & $5.08 \times 10^{4}$ & 2.7 & 6290 \\
\hline 44 & $\mathrm{H}_{2}+\mathrm{OH}=\mathrm{H}_{2} \mathrm{O}+\mathrm{H}$ & $2.16 \times 10^{8}$ & 1.5 & 3430 \\
\hline 45 & $\mathrm{O}+\mathrm{H}_{2} \mathrm{O}=\mathrm{OH}+\mathrm{OH}$ & $2.97 \times 10^{6}$ & 2.0 & 13400 \\
\hline 46 & $\mathrm{H}_{2}+\mathrm{M}=\mathrm{H}+\mathrm{H}+\mathrm{M}$ & $4.58 \times 10^{19}$ & -1.4 & 104380 \\
\hline 47 & $\mathrm{O}+\mathrm{O}+\mathrm{M}=\mathrm{O}_{2}+\mathrm{M}$ & $6.16 \times 10^{15}$ & -0.5 & 0.0 \\
\hline 48 & $\mathrm{O}+\mathrm{H}+\mathrm{M}=\mathrm{OH}+\mathrm{M}$ & $4.71 \times 10^{18}$ & -1.0 & 0.0 \\
\hline 49 & $\mathrm{H}+\mathrm{OH}+\mathrm{M}=\mathrm{H}_{2} \mathrm{O}+\mathrm{M}$ & $3.8 \times 10^{22}$ & -2.0 & 0.0 \\
\hline 50 & $\mathrm{H}+\mathrm{O}_{2}+\mathrm{M}=\mathrm{HO}_{2}+\mathrm{M}$ & $1.48 \times 10^{12}$ & 0.6 & 0.0 \\
\hline
\end{tabular}




\begin{tabular}{|c|c|c|c|c|}
\hline 51 & $\mathrm{HO}_{2}+\mathrm{H}=\mathrm{H}_{2}+\mathrm{O}_{2}$ & $1.66 \times 10^{13}$ & 0.0 & 823 \\
\hline 52 & $\mathrm{HO}_{2}+\mathrm{H}=\mathrm{OH}+\mathrm{OH}$ & $7.08 \times 10^{13}$ & 0.0 & 295 \\
\hline 53 & $\mathrm{HO}_{2}+\mathrm{O}=\mathrm{O}_{2}+\mathrm{OH}$ & $3.25 \times 10^{13}$ & 0.0 & 0.0 \\
\hline 54 & $\mathrm{HO}_{2}+\mathrm{OH}=\mathrm{H}_{2} \mathrm{O}+\mathrm{O}_{2}$ & $2.89 \times 10^{13}$ & 0.0 & -497 \\
\hline 55 & $\mathrm{HO}_{2}+\mathrm{HO}_{2}=\mathrm{H}_{2} \mathrm{O}_{2}+\mathrm{O}_{2}$ & $4.2 \times 10^{14}$ & 0.0 & 11982 \\
\hline 56 & $\mathrm{HO}_{2}+\mathrm{HO}_{2}=\mathrm{H}_{2} \mathrm{O}_{2}+\mathrm{O}_{2}$ & $1.3 \times 10^{11}$ & 0.0 & -1629.3 \\
\hline 57 & $\mathrm{H}_{2} \mathrm{O}_{2}+\mathrm{M}=\mathrm{OH}+\mathrm{OH}+\mathrm{M}$ & $2.95 \times 10^{14}$ & 0.0 & 48430 \\
\hline 58 & $\mathrm{H}_{2} \mathrm{O}_{2}+\mathrm{H}=\mathrm{H}_{2} \mathrm{O}+\mathrm{OH}$ & $2.41 \times 10^{13}$ & 0.0 & 3970 \\
\hline 59 & $\mathrm{H}_{2} \mathrm{O}_{2}+\mathrm{H}=\mathrm{HO}_{2}+\mathrm{H}_{2}$ & $4.82 \times 10^{13}$ & 0.0 & 7950 \\
\hline 60 & $\mathrm{H}_{2} \mathrm{O}_{2}+\mathrm{O}=\mathrm{OH}+\mathrm{HO}_{2}$ & $9.55 \times 10^{6}$ & 2.0 & 3970 \\
\hline 61 & $\mathrm{H}_{2} \mathrm{O}_{2}+\mathrm{OH}=\mathrm{HO}_{2}+\mathrm{H}_{2} \mathrm{O}$ & $1.0 \times 10^{12}$ & 0.0 & 0.0 \\
\hline 62 & $\mathrm{H}_{2} \mathrm{O}_{2}{ }^{+} \mathrm{OH}=\mathrm{HO}_{2}{ }^{+} \mathrm{H}_{2} \mathrm{O}$ & $5.8 \times 10^{14}$ & 0.0 & 9557 \\
\hline 63 & $\mathrm{CO}+\mathrm{O}+\mathrm{M}=\mathrm{CO}_{2}+\mathrm{M}$ & $1.8 \times 10^{10}$ & 0.0 & 2384 \\
\hline 64 & $\mathrm{CO}+\mathrm{O}_{2}=\mathrm{CO}_{2}+\mathrm{O}$ & $2.53 \times 10^{12}$ & 0.0 & 47700 \\
\hline 65 & $\mathrm{CO}+\mathrm{HO}_{2}=\mathrm{CO}_{2}+\mathrm{OH}$ & $3.01 \times 10^{13}$ & 0.0 & 23000 \\
\hline 66 & $\mathrm{CO}+\mathrm{OH}=\mathrm{CO}_{2}+\mathrm{H}$ & $2.23 \times 10^{5}$ & 1.9 & -1158.7 \\
\hline
\end{tabular}

